\title{
PEMANFAATAN BIOGAS TERMURNIKAN BERBASIS METODE KALSINASI PADA KENDARAAN BERMOTOR
}

\author{
Rudy Sutanto*, I Gst Bagus Dipa Maha Putra**, Arif Mulyanto*** \\ Jurusan Teknik Mesin Fakultas Teknik Universitas Mataram \\ Jln. Majapahit No.62 Mataram Nusa Tenggara Barat Kode Pos: 83125 \\ Telp. (0370) 636087; 636126; ext 128 Fax (0370) 636087
}

\begin{abstract}
Biogas is one of the alternative energy sources that are environmentally friendly, inexpensive, easily available, renewable, and can be used as a substitute for gasoline for motor gasoline. For the use of biogas in the motor gasoline is necessary to improve the quality of biogas that is more optimal use of biogas when used as fuel.

This study aims to determine the reduction of carbon dioxide $\left(\mathrm{CO}_{2}\right)$ during the purification of biogas by using absorber $\mathrm{Ca}(\mathrm{OH})_{2}$ to the elevated levels of $\mathrm{CH}_{4}$ in biogas and its effect when testing the performance of the motor fuel, which indicate the performance of the motor fuel is the torque, power and effective specific Fuel Consumption effective. In this study, the biogas will be purified by varying the flow rate is var I (5 liters / min), var II (10 Itr / min) and var III (15 Itr / min), and biogas purification degan best quality results will be compared with biogas before purification by way of testing the motor performance in round $1500 \mathrm{rpm}, 2500 \mathrm{rpm}, 3500 \mathrm{rpm}$ and $4500 \mathrm{rpm}$.

The result showed that the purification of biogas menggunan $\mathrm{Ca}(\mathrm{OH})_{2}$ at a rate var II (10 Itr / min) produced the best biogas $\mathrm{CH}_{4}$ content of $91.0 \%$, better than the variations I and III variations, and the results of performance testing of the motor fuel showed improvement menghasillkan better quality. Judging from rotation $4500 \mathrm{rpm}$ for prior purification $5.9399 \mathrm{Nm}$ torque, power and SFCe effective $2797.7079 \mathrm{~W} 0.000164$ (kg / jam.W), whereas after purification $6.5821 \mathrm{Nm}$ torque, effective power $3100.1628 \mathrm{~W}$ and SFCe 0.000113 (kg / jam.W)
\end{abstract}

Keywords: Biogas, absorbs, $\mathrm{Ca}(\mathrm{OH}) 2$ biogas flow rate, engine performance

\section{PENDAHULUAN}

Krisis energi merupakan salah satu masalah yang sedang dihadapi saat ini, terutama berkenaan dengan menipisnya cadangan minyak bumi dan kebutuhan energi di dunia hingga saat ini bergantung pada bahan bakar fosil. Kelangkaan bahan bakar minyak, yang salah satunya disebabkan oleh kenaikan harga minyak dunia yang signifikan, telah mendorong pemerintah untuk mengajak masyarakat mengatasi masalah energi secara bersamasama. Makin meningkatnya harga bahan bakar minyak dan bahan bakar gas untuk memenuhi kebutuhan rumah tangga, ini mendorong pemikiran untuk pencarian sumber energi alternatif.

Indonesia sebagai negara yang memiliki sumber daya pertanian dan peternakan yang cukup besar. Sumber daya tersebut ,selain di gunakan untuk kebutuhan pangan juga dapat berpotensi sebagai sumber energi dengan cara pemanfaatan kotoran ternak, menjadi biogas.

Biogas adalah gas yang dihasilkan oleh aktivitas anaerobik atau fermentasi dari bahan-bahan organik termasuk diantaranya; kotoran manusia dan hewan, limbah domestik (rumah tangga), sampah biodegradable atau setiap limbah organik yang biodegradable dalam kondisi anaerobik. Kandungan utama dalam biogas adalah metana dan karbon dioksida. Biogas dapat digunakan sebagai bahan bakar kendaraan maupun untuk menghasilkan listrik.

Degradasi secara mikrobiologi dari bahan-bahan organik dalam lingkungan anaerob hanya dapat dilakukan oleh mikroorganisme yang mampu memanfaatkan molekul selain oksigen sebagai akseptor hidrogen. Dekomposisi anaerob menghasilkan biogas yang terdiri dari metana (50-70\%), karbondioksida (25$45 \%$ ) (Prince dan Cheremisinoff, 1981).

Media pengembangan peternakan NTB mencatat bahwa jumlah populasi kuda untuk wilayah Mataram dan Lombok Barat mencapai 5150 ekor dengan potensi kotoran $2 \mathrm{~kg}$ per ekor/hari, berarti total produksi kotoran kuda mencapai 10,3 ton/hari, jumlah yang cukup potensial sebagai bahan baku pembuatan biogas.

Tujuan dari penelitian ini adalah ingin mengetahui bagaimana pengaruh 
peningkatan kadar $\left(\mathrm{CH}_{4}\right)$ pada biogas dengan menggunakan metode kalsinasi (absorber : media $\mathrm{Ca}(\mathrm{OH}) 2$ terhadap unjuk kerja motor bakar.

Melalui penelitian ini di harapkan dapat memberikan gambaran serta pengetahuan tentang bagaimana pengaruh peningkatan gas metan $\mathrm{CH} 4$ pada biogas terhadap unjuk kerja motor bakar.

\section{LANDASAN TEORI}

Biogas merupakan bahan bakar gas (biofuel) dan bahan bakar yang dapat diperbaharui (renewable fuel) yang dihasilkan secara anaerobic digestion atau fermentasi anaerob dari bahan organik dengan bantuan bakteri metana seperti Methanobacterium sp. Bahan yang dapat digunakan sebagai bahan baku pembuatan biogas yaitu bahan biodegradable seperti biomassa (bahan organik bukan fosil), kotoran, sampah padat hasil aktivitas perkotaan dan lain-lain. Akan tetapi, biogas biasanya dibuat dari kotoran ternak seperti kerbau, sapi, kambing, kuda dan lain - lain. Kandungan utama biogas adalah gas metana $\left(\mathrm{CH}_{4}\right)$ dengan konsentrasi sebesar 50 - $80 \%$ vol. Gas dalam biogas yang dapat berperan sebagai bahan bakar yaitu gas metana $\left(\mathrm{CH}_{4}\right)$, gas hidrogen $\left(\mathrm{H}_{2}\right)$ dan gas karbon monoksida (CO) (price and Cheremisinoff,.1981).

Proses pembuatan biogas dilakukan secara fermentasi yaitu proses terbentuknya gas metana dalam kondisi anaerob dengan bantuan bakteri anaerob di dalam suatu digester sehingga akan dihasilkan gas metana $\left(\mathrm{CH}_{4}\right)$ dan gas karbon dioksida $\left(\mathrm{CO}_{2}\right)$ yang volumenya lebih besar dari gas hidrogen $\left(\mathrm{H}_{2}\right)$, gas nitrogen $\left(\mathrm{N}_{2}\right)$ dan gas hydrogen sulfida $\left(\mathrm{H}_{2} \mathrm{~S}\right)$. Proses fermentasi memerlukan waktu 7 sampai 10 hari untuk menghasilkan biogas dengan suhu optimum $35{ }^{\circ} \mathrm{C}$ dan $\mathrm{pH}$ optimum pada range $6,4-$ 7,9. Bakteri pembentuk biogas yang digunakan yaitu bakteri anaerob seperti Methanobacterium, Methanobacillus, Methanococcus dan Methanosarcina (Price and Paul, 1981). Biogas yang dibuat dari kotoran ternak sapi mengandung gas $\mathrm{CH} 4$ sebesar 55 - $65 \%$, gas $\mathrm{CO}_{2}$ sebesar $30-$ $35 \%$ dan sedikit gas hidrogen $\left(\mathrm{H}_{2}\right)$, gas nitrogen $\left(\mathrm{N}_{2}\right)$ dan gas - gas lain. Panas yang dihasilkan sebesar 600 BTU/cuft. Sedangkan, biogas yang dibuat dari gas alam mengandung gas $\mathrm{CH}_{4}$ sebesar $80 \%$ dengan panas sebesar 1000 BTU/cuft. Kandungan gas $\mathrm{CH}_{4}$ dari biogas dapat ditingkatkan dengan memisahkan gas $\mathrm{CO}_{2}$ dan gas $\mathrm{H}_{2} \mathrm{~S}$ yang bersifat korosif (http://www.sciencedirect.com/, 2007).

Menurut Wellinger and Lindenberg (2000), komposisi biogas yang dihasilkan sangat tergantung pada jenis bahan baku yang digunakan. Namun demikian, komposisi biogas yang utama adalah gas metana $\left(\mathrm{CH}_{4}\right)$ dan gas karbon dioksida $\left(\mathrm{CO}_{2}\right)$ dengan sedikit hidrogen sulfida $\left(\mathrm{H}_{2} \mathrm{~S}\right)$. Komponen lainnya yang ditemukan dalam kisaran konsentrasi kecil (trace element) antara lain senyawa sulfur organik, senyawa hidrokarbon terhalogenasi (Halogenated hydrocarbons), gas hidrogen $\left(\mathrm{H}_{2}\right)$, gas nitrogen $\left(\mathrm{N}_{2}\right)$, gas karbon monoksida (CO) dan gas oksigen $\left(\mathrm{O}_{2}\right)$. Berikut ini tabel mengenai komposisi utama yang terdapat dalam biogas.

\begin{tabular}{|c|c|c|c|c|c|}
\hline \multirow[t]{2}{*}{ No. } & \multirow[t]{2}{*}{ Komponen } & \multirow[t]{2}{*}{ Satuan } & \multicolumn{3}{|c|}{ Komposisi } \\
\hline & & & $1^{3}$ & $2^{m}$ & $3^{m m}$ \\
\hline 1. & Gas Methan $\left(\mathrm{CH}_{4}\right)$ & $\% \mathrm{Vol}$ & $55-75$ & $50-75$ & $54-70$ \\
\hline 2. & Karbon dioksida $\left(\mathrm{CO}_{2}\right)$ & $\% \mathrm{Vol}$ & $24-45$ & $24-40$ & $27-45$ \\
\hline 3. & Nitrogen $\left(\mathrm{N}_{2}\right)$ & $\% \mathrm{Vol}$ & $0-0,3$ & $<2$ & $0-1$ \\
\hline 4. & Hidrogen $\left(\mathrm{H}_{2}\right)$ & $\% \mathrm{Vol}$ & $1-5$ & $<1$ & $0-1$ \\
\hline 5. & Karbon monoksida (CO) & $\% \mathrm{Vol}$ & & & 0,1 \\
\hline 6. & Oksigen $\left(\mathrm{O}_{2}\right)$ & Ppm & $0,1-0,5$ & $<2$ & 0,1 \\
\hline 7. & Hidrogen sulfida $\left(\mathrm{H}_{2} \mathrm{~S}\right)$ & Ppm & 0.3 & $<2$ & Sedikit \\
\hline \multicolumn{6}{|c|}{ 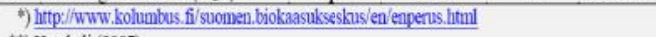 } \\
\hline & $\begin{array}{l}\text { ambali (2007) } \\
\text { Vidarto (1997) }\end{array}$ & & & & \\
\hline
\end{tabular}

Pemurnian biogas menjadi sebuah pertimbangan yang sangat penting untuk mengurangi kadar gas selain $\mathrm{CH}_{4}$ pada hasil pengolahan biogas karena berpengaruh terhadap nilai kalor/panas yang dihasilkan, sehingga $\mathrm{CH}_{4}$ yang dihasilkan perlu dilakukan permurnian terhadap pemurnianpemurnian yang lain. Dalam hal ini pemurnian yang berpengaruh terhadap nilai kalor/panas adalah $\mathrm{CO}_{2}$, keberadaan gas $\mathrm{CO}_{2}$ dalam gas $\mathrm{CH}_{4}$ sangat tidak diinginkan, hal ini dikarenakan semakin tinggi kadar $\mathrm{CO}_{2}$ dalam $\mathrm{CH}_{4}$ maka akan semakin menurunkan nilai kalor $\mathrm{CH}_{4}$ dan sangat mengganggu dalam proses pembakaran, hal ini menyebabkan kemurnian $\mathrm{CH}_{4}$ menjadi rendah.

$$
\mathrm{Ca}(\mathrm{OH})_{2}+\mathrm{CO}_{2} \longrightarrow \mathrm{CaCO}_{3}+\mathrm{H}_{2} \mathrm{O}
$$

Pemurnian menggunakan $\mathrm{Ca}(\mathrm{OH}) 2$ adapun reaksinya seperti di atas ,karbon dioksida akan di serap menggunakan absorber $\mathrm{Ca}(\mathrm{OH})_{2}$, untuk menurunkan kadar $\mathrm{CO} 2$ yang terdapat pada biogas.

Kalsium hidroksida adalah senyawa kimia dengan rumus kimia $\mathrm{Ca}(\mathrm{OH})_{2}$. Kalsium hidroksida dapat berupa kristal tak berwarna atau bubuk putih. Dalam bahasa inggris, kalsium hidroksida juga di namakan slaked 
lime, atau hydrated lime (kapur yang di airkan). Larutan $\mathrm{Ca}(\mathrm{OH})_{2}$ di sebut air kapur dan merupakan basa dengan kekuatan sedang.

Larutan tersebut bereaksi dengan berbagai asam, dan bereaksi dengan banyak logam dengan adanya air. Larutan tersebut menjadi keruh bila di lewatkan karbon dioksida, karena mengendapnya kalsium karbonat (http://digilib.petra.ac.id, 2003).

$$
\begin{aligned}
\mathrm{CaO} & +\mathrm{H}_{2} \mathrm{O} \longrightarrow \mathrm{Ca}(\mathrm{OH})_{2} \\
56 \frac{\mathrm{gr}}{\mathrm{mol}} 18 \frac{\mathrm{gr}}{\mathrm{mol}} & 74 \frac{\mathrm{gr}}{\mathrm{mol}} \\
\mathrm{Ca}(\mathrm{OH})_{2}+\mathrm{CO}_{2} & \longrightarrow \mathrm{CaCO}_{3}+\mathrm{H}_{2} \mathrm{O}
\end{aligned}
$$

Seperti kita ketahui roda-roda suatu kendaraan memerlukan adanya sumber tenaga luar yang memungkinkan kendaraan dapat bergerak serta dapat mengatasi keadaan jalan, udara dan sebagainya. Sumber dari luar yang menghasilkan tenaga disebut mesin. Mesin merupakan alat yang merubah sumber tenaga panas, listrik, air, angin, tenaga atom, atau sumber tenaga lainya menjadi tenaga mekanik (mechanical energy). Mesin yang merubah tenaga panas menjadi tenaga mekanik disebut motor bakar (thermal engine). (Arismunandar, 1998).

Dalam sejarah perkembangannya, motor bakar torak yang termasuk dalam kelompok motor pembakaran dalam merupakan mesin penggerak mula yang ringan dan kompak meskipun mesin pancar gas menempati posisi yang terbaik sebagai mesin propulsi pesawat terbang, namun motor bakar torak masih unggul sebagai mesin penggerak kendaraan bermotor, kereta api, kapal, mesin konstruksi, mesin pertanian, generator listrik dan lain sebagainya. Sampai saat ini motor bakar torak terbagi menjadi dua jenis yaitu :

1. Motor bakar dua langkah (two stroke engine)

Yaitu setiap siklus kerja dari motor terjadi dalam dua langkah torak atau satu kali putaran poros engkol $\left(360^{\circ}\right.$ poros engkol).

2. Motor bakar empat langkah (four stroke engine)

Yaitu setiap siklus kerja dari motor terjadi dalam empat langkah torak atau dua kali putaran poros engkol $\left(720^{\circ}\right.$ poros engkol).

\section{Conversion Kit}

Conversion kit atau dikenal juga dengan nama konversi kit merupakan peralatan tambahan pada motor bakar sehingga motor tersebut dapat beroperasi menggunakan BBG. (Tirtoatmodjo; et, al, 1999).

Penggunaan conversion kit didasarkan pada tiga pilihan sebagai berikut:

1. Hanya bekerja dengan bahan bakar gas saja.

2. Dapat bekerja dengan gas saja atau gasoline saja ( dual fuel ).

3. Dapat bekerja dengan dua bahan bakar bersama-sama (khusus diesel, mixed fuel).

Komponen-komponen perangkat konversi BBG tersebut terdiri dari tangki penyimpan BBG, regulator (pengatur tekanan), mixer (pencampur udara dan bahan bakar). Pada gambar di bawah ini ditunjukkan skema sistem perangkat konversi berbahan bakar ganda (dual fuel) pada kendaraan bermotor. (Kristanto; et, al, 2001).

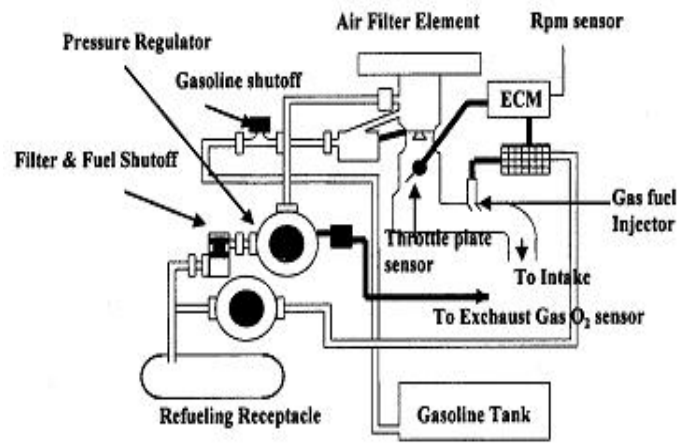

Gambar 2 Skema conversion kit sistem injeksi. (Kristanto; et, al, 2001).

Alat Ukur Torsi (Torsi Meter)

Alat ukur torsi adalah alat yang digunakan untuk mengukur besarnya torsi dan daya aktual dari suatu poros yang bekerja pada putaran konstan. Secara umum prinsip kerja alat ukur torsi yaitu putaran dari poros engkol diteruskan ke transmisi melalui kopling. Poros keluaran dari transmisi digabung langsung dengan sproket penggerak sehingga menggerakkan sproket belakang yang berhubungan langsung dengan tromol roda belakang melalui perantara rantai (chain). Dengan memberikan beban pengereman pada tromol roda belakang yang nilainya dapat dibaca melalui neraca ukur (neraca pegas, dengan satuan $\mathrm{kg}$ ), maka nilai torsi dapat dicari dengan mengalikan besarnya beban pengereman dan panjang lengan ( $\mathrm{mm}$ ) yang dirumuskan sebagai berikut (Heywood, 1988): 


$$
\begin{aligned}
& T=F \times L(N . m) \\
& \text { dengan : } \\
& \mathrm{L}: \text { Panjang lengan, }(\mathrm{m}) \\
& \mathrm{F}: \text { Gaya tangensial stator, }(\mathrm{N})
\end{aligned}
$$

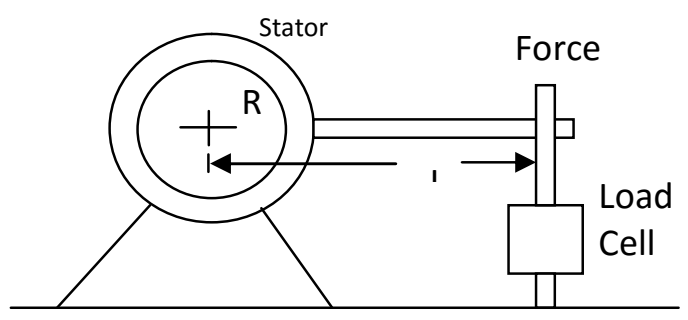

Gambar 3 Prinsip kerja alat ukur torsi.

(Heywood, 1988)

Daya Efektif $(\mathrm{Ne})$

Besarnya daya efektif $(\mathrm{Ne})$ akan tergantung dari besarnya torsi dan putaran yang terjadi. Hal ini dapat dilihat dari persamaan berikut (Arismunandar, 1998):

$N e=\frac{2 \pi \times T \times n}{60}($ Watt $)$.

dengan :

$$
\begin{array}{ll}
\mathrm{Ne} & : \text { Daya efektif (Watt) } \\
\mathrm{T} & : \text { Torsi (N) } \\
\mathrm{n} & : \text { Putaran mesin (rpm) }
\end{array}
$$

Specific Fuel Consumption Effective (SFCe)

Konsumsi bahan bakar efektif atau specific fuel consumption effective (SFCe) ditentukan dengan persamaan (Anonim 6, 2001):

$$
\text { SFCe }=\frac{F C}{N e} \ldots .(\mathrm{kg} / \mathrm{jam} . \mathrm{W})
$$

dengan :

$$
\begin{aligned}
& \text { FC : Penggunaan bahan bakar } \\
& \text { kondisi tertentu, (kg / jam) } \\
& \mathrm{Ne} \text { : Daya efektif, (Watt) }
\end{aligned}
$$

pada

SFCe sebagai parameter yang biasa dipakai sebagai ukuran ekonomi pemakaian bahan bakar yang dipakai per jam untuk setiap daya yang dihasilkan. Harga SFCe yang lebih rendah menyatakan efisiensi yang lebih tinggi.

\section{METODE PENELITIAN}

Alat yang digunakan dalam penelitian ini adalah biogas tester, motor honda supra $\mathrm{x}$, alat ukur torsi, neraca digital,digester, plastik penampung, selang,katup manual,tabung Ip3, pompa vakum ,kompresor, dan conversion kit.

Adapun bahan dalam penelitian ini antara lain biogas, kapur $\mathrm{Ca}(\mathrm{OH})_{2}$ dan air.

Pada penelitian ini membandingkan biogas yang tanpa perlakuan pemurnian dengan menggunakan pemurnian dengan absorber $\mathrm{Ca}(\mathrm{OH}) 2$.

Pemurnian biogas menggunakan tiga variasi laju aliran pemurnian biogas yaitu $5 \mathrm{litr} / \mathrm{mnt}, 10 \mathrm{litr} / \mathrm{mnt}$, dan $15 \mathrm{litr} / \mathrm{mnt}$. Pemurnian biogas menggunakan $\mathrm{Ca}(\mathrm{OH}) 2$ setelah di lakukan pengujian biogas . Hasil kadar $\mathrm{CH} 4$ yang terbaik akan di ambil untuk di uji pada motor.

Kemudian membandingkan hasil pengujian pada motor dengan menggunakan bahan bakar biogas yang belum di murnikan dan sudah di murnikan dan setelah itu melakukan analisa data dan menarik kesimpulan.

\section{HASIL DAN PEMBAHASAN}

Pengujian komposisi biogas di Laboratorium Enegi Baru Terbarukan Fakultas Teknik Universitas Mataram. Pengujian komposisi biogas untuk mengetahui komposisi biogas dan mengetahui penyerapan kadar $\mathrm{CO} 2$ dan komposisi terbaik yang akan diambil dan di uji pada kendaraan bermotor. Berikut data dan grafik yang diperoleh pada pengujian komposisi biogas. pemurnian biogas menggunakan $\mathrm{Ca}(\mathrm{OH})_{2}$ dapat mereduksi $\mathrm{CO}_{2}$ hingga $0,0 \%$ dan membentuk gas lain , dengan berkuranganya kadar $\mathrm{CO}_{2}$ ini otomatis akan meningkatkan kadar $\mathrm{CH}_{4}$. Peningkatan kadar $\mathrm{CH}_{4}$ pada biogas berbanding terbalik dengan komposisi gas lain, itu disebabkan oleh kadar $\mathrm{CO}_{2}$ yang sudah habis terserap $\mathrm{Ca}(\mathrm{OH})_{2}$. Fenomena yang terjadi mungkin disebabkan oleh penurunan laju aliran biogas sehingga kadar gas lain menurun, sehingga kadar $\mathrm{CH}_{4}$ pun berangsur meningkat. 


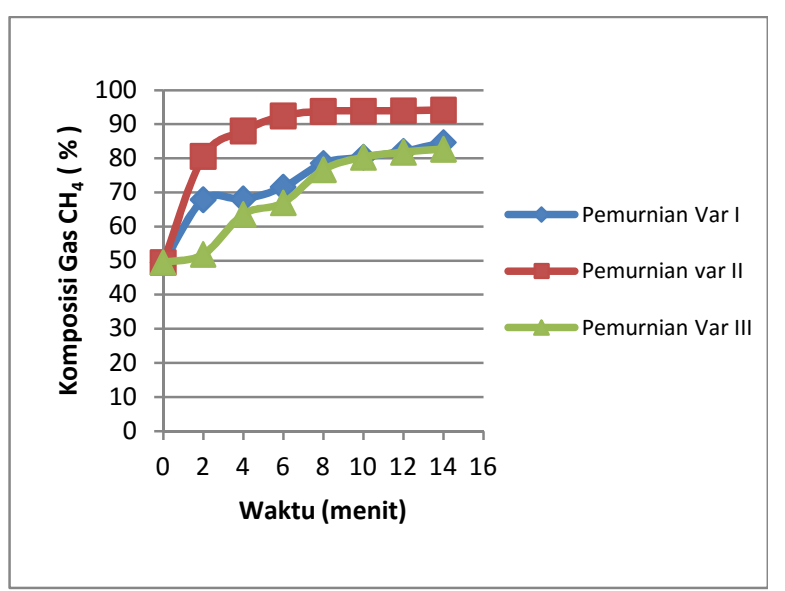

Grafik 4.1: Grafik hubungan waktu pemurnian dengan konsentrasi kadar gas $\mathrm{CH}_{4}$ dalam Biogas

\section{Kecendrungan peningkatan pada setiap perlakuan yang dilakukan} membuktikan bahwa setiap variasi memiliki kemampuan untuk mereduksi gas selain $\mathrm{CH}_{4}$ pada biogas. Hasil ini terlihat pada grafik dengan kecendrungan peningkatan kadar gas $\mathrm{CH}_{4}$ meskipun untuk setiap variasi yang dilakukan terdapat perbedaan peningkatan yang diadapatkan peningkatan yang berbeda. Pada grafik 4.1 terlihat bahwa kadar komposisi $\mathrm{CH}_{4}$ pada biogas terbesar ada pada variasi kedua yaitu dengan persentase rata-rata $91.0 \%$ pada kecepatan laju alir 10 liter/menit, kemudian persentase rata-rata variasi pertama dengan $76,2 \%$ pada kecepatan laju 5 liter/menit dan yang terakhir di dapat persentase rata-rata variasi ketiga dengan $72,0 \%$ pada kecepatan 15 liter/menit. Dalam hal ini terlihat bahwa kadar $\mathrm{CH}_{4}$ terbesar pada variasi II dan terkecil pada variasi III.

Jika indikasi kadar $\mathrm{CH}_{4}$ meningkat pervolume biogas yang terukur oleh biogas teser maka akan ada gas selain gas $\mathrm{CH}_{4}$ yang akan tereduksi pada saat proses pemurnian yang terjadi, dari data penelitian dapat juga dilihat kadar $\mathrm{CO}_{2}$ untuk setiap variasi seperti pada grafik 4.2 .

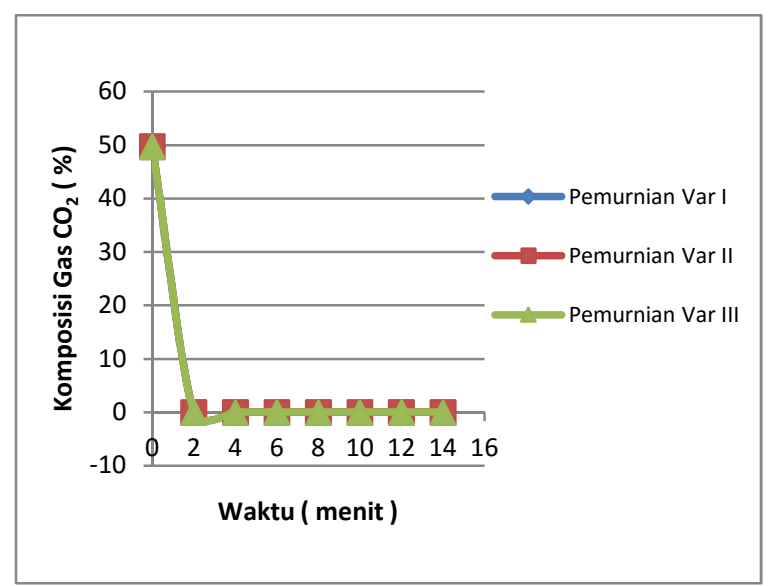

Grafik 4.2 : Grafik hubungan waktu pemurnian dengan konsentrasi kadar gas $\mathrm{CO}_{2}$ dalam Biogas

Jika dilihat dari kadar $\mathrm{CO}_{2}$ yang terbaca oleh biogas tester, dimana pada setiap variasi memiliki hasil yang sama, dimana semua gas $\mathrm{CO}_{2}$ yang berada dalam biogas tereduksi secara maksimal oleh $\mathrm{Ca}(\mathrm{OH})_{2}$, hal ini terlihat dari data gas $\mathrm{CO}_{2}$ pada setiap variasi $0 \%$. Dengan persentase yang seperti ini maka gas $\mathrm{CO}_{2}$ tidak mempengaruhi kadar gas $\mathrm{CH}_{4}$ dalam pemurnian karena setiap variasi memiliki kemampuan yang sama untuk mereduksi kadar gas $\mathrm{CO}_{2}$.

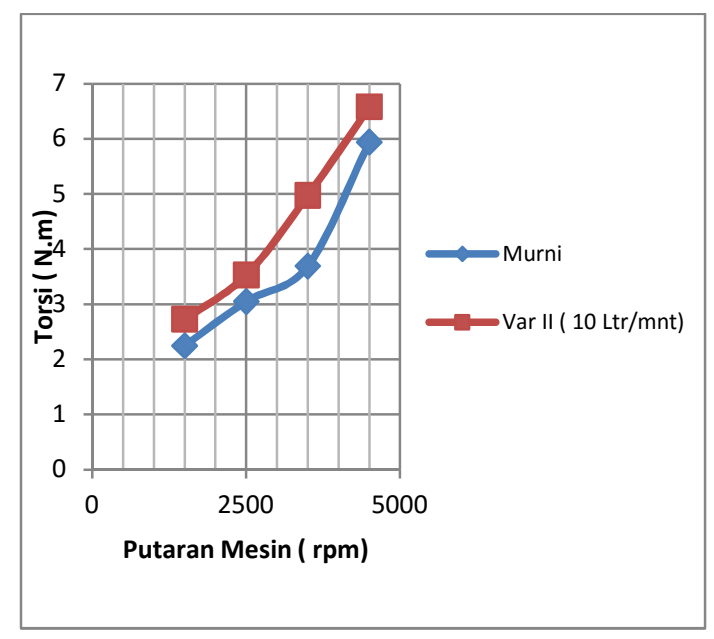

Grafik 4.5 : Hubungan antara putaran mesin dengan Torsi untuk biogas sebelum dan sesudah permurnian.

Pada grafik terlihat bahwa untuk setiap variasi menghasilkan Torsi yang berbeda, dimana untuk setiap kenaikan putaran mesin di imbangi dengan kanaikan Torsi pada saat pengujian berlangsung. Pada putaran 1500 rpm terllihat bahwa Torsi mengunakan biogas sebelum pemurnian 
memiliki perbedaan yang kecil dengan yang telah dimurnikan dimana sebelum permurnian menghasilkan 2.2475 N.m sedengkan setelah pemurnian menghasilkan Torsi sebesar 2.7292 N.m, perbedaan antara Torsi yang dihasilkan pada putaran rendah sangat kecil dibandingkan yang lain sehingga pada putaran rendah perbedaan Torsi antara biogas sebelum pemurnian dan setelah permurnian signifikan perbedaanya. Jika melihat grafik 4.5 dimana terlihat semakin tinggi putaran mesin yang diujikan semakin jauh perbedaan antara kedua bahan bakar biogas tersebut, dimana pada putaran 4500 rpm pada biogas sebelum dimurnikan menghasilkan torsi sebesar 5.9399 N.m sedangkan pada biogas setelah pemurnian menghasilkan 6.5821 N.m.

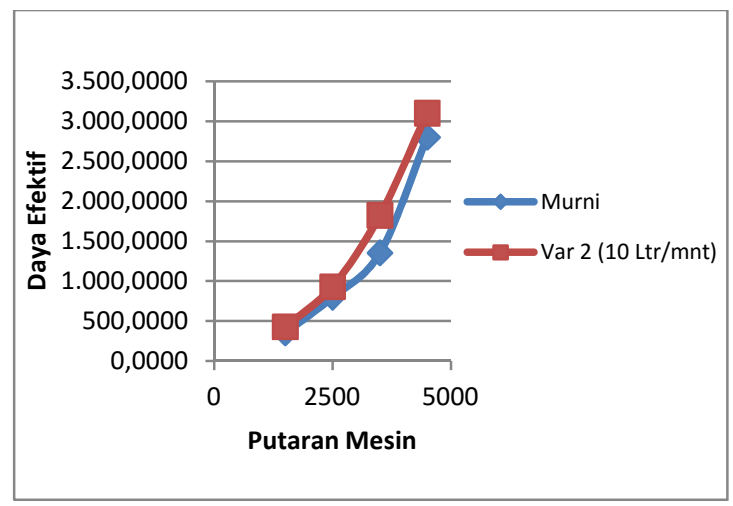

Grafik 4.5 : Hubungan antara putaran mesin dengan daya efektif untuk biogas sebelum dan sesudah permurnian.

Pada grafik terlihat bahwa untuk setiap variasi menghasilkan daya efektif yang berbeda, dimana untuk setiap kenaikan putaran mesin di imbangi dengan kanaikan daya efektif pada saat pengujian berlangsung. Pada putaran 1500 rpm terllihat bahwa daya efektif mengunakan biogas sebelum pemurnian memiliki perbedaan yang kecil dengan yang telah dimurnikan dimana sebelum permurnian menghasilkan 352,8641 W sedangkan setelah pemurnian menghasilkan daya efektif sebesar $428,4778 \mathrm{~W}$, perbedaan antara daya efektif yang dihasilkan pada putaran rendah sangat kecil dibandingkan yang lain sehingga pada putaran rendah perbedaan daya efektif antara biogas sebelum pemurnian dan setelah permurnian tidak terlalu jauh. Jika melihat grafik 4.5 dimana terlihat semakin tinggi putaran mesin yang diujikan semakin jauh perbedaan antara kedua bahan bakar biogas tersebut, dimana pada putaran 4500 rpm pada biogas sebelum dimurnikan menghasilkan daya efektif sebesar 2797,7079 W sedangkan pada biogas setelah pemurnian menghasilkan 3100,1628 W.

Dari data yang didapat diatas dan terlihat dalam grafik bahwa semakin tinggi putaran mesin maka daya efektif semakin besar, dan terlihat bahwa pemurnian biogas memberikan pengaruh ketika diuji pada motor dengan menghasilkan Daya Efektif yang lebih baik dari pada biogas sebelum dimurnikan.

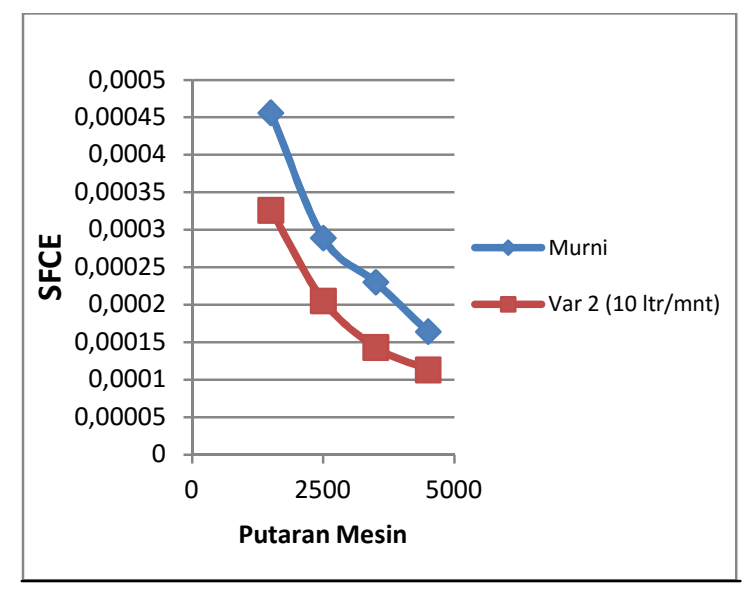

Grafik 4.6 : Hubungan Putaran mesin dengan Spesifik Feul Consumsion ( SFCe ) pada biogas sebelum dan sesudah pemurnian.

Dari grafik 4.6 terlihat bahwa konsumsi bahan bakar untuk variasi II atau setelah pemurnian lebih sedikit menggunakan bahan bakar dari pada sebelum pemurnian, hal ini menunjukkan bahwa peningkatan kadar $\mathrm{CH} 4$ pada biogas mempengaruhi konsumsi bahan bakar. Jika melihat dari setiap variasi putaran yang diberikan selama pengujian berlangsung tidak ada satupun dari biogas murni yang mengkonsumsi bahan bakar sama atau lebih sedikit dari pada biogas yang telah dimurnikan.

\section{KESIMPULAN}

1. Berdasarkan hasil pengujian dari seluruh pemurnian mulai dari variasi I hingga variasi III menunjukkan adanya peningkatan kadar gas metana $\left(\mathrm{CH}_{4}\right)$ pada setiap komposisi hasil variasi yaitu variasi I $76,2 \%$ rata-rata variasi II $91,0 \%$ dan rata-rata variasi III 72,0\%.

2. Pemurnian pada variasi II dengan kecepatan 10 liter/menit manghasilkan hasil pemurnian dengan kadar $\mathrm{CH}_{4}$ 
terbanyak dengan nilai rata-rata $91,0 \%$ dan variasi III menghasilkan kadar $\mathrm{CH}_{4}$ terendah yaitu $72,0 \%$ dengan kecepatan 15 liter/menit.

3. Variasi permurnian I,II, dan III semua mereduksi kadar $\mathrm{CO}_{2}$ dalam biogas hingga mencapi kadar CO2 0,0\% .

4. Setelah melakukan pengujian menunjukkan variasi II menghasilkan daya efektif yang lebih baik dari biogas sebelum pemurnian pada setiap variasi putaran yang diberikan.

5. SFCe yang gunakan pada variasi II lebih rendah dari pada biogas sebelum pemurnian disetiap variasi putaran yang diberikan.

6. Peningkatan kadar gas $\mathrm{CH} 4$ pada biogas setelah dilakukan pemurnian menghasilkan daya yang lebih baik dan konsumsi bahan bakar yang lebih rendah dari biogas sebelum pemurnian.

\section{SARAN}

Proses pemurnian biogas sebaiknya menggunkan absorber dalam bentuk cetakan, agar lebih mudah menggantinya apa bila sudah habis bereaksi .Untuk pengujian pada motor masih menggunakan conversion kit manual di anjurkan menggunakan yang otomatis agar konsumsi bahan bakar dapat ditekan.

\section{DAFTAR PUSTAKA}

Anonim 1., 2001, Buku Petunjuk Praktikum Motor Bakar, Malang; Jurusan Teknik Mesin FT-Universitas Brawijaya.

Arismunandar. Wiranto, Prof, Dr., 1988, Motor Bakar Torak, Bandung; ITB Bandung.

Fry, L. John, (1973) Methane Digesters for Fuel Gas and Fertilizer. Privately published.
Harasimowicz,M.P.Orluk, 2007, Application Of Polymide, Membranes for Biogas Purification, Journal Of Hazar Dous Materials,

Haryono, 2007, Diktat Kuliah Pirometalurgi, Cilegon; FT-UNTIRTA..

Heywood. John, B. Prof, Dr., 1988, Internal Combustion Engine Fundamental, Singapore; Mc Graw-Hill book company Inc.

Hobson, P.N., Bousfield, S., Summers, R., (1981) Applied Science Publishers Ltd., Essex, England.

Kristanto. Philip., Gunawan. Jemy., 2001, Pengaturan Kondisi Idle dan Akselerasi pada Motor Berbahan Bakar Gas, Jurnal Teknik Mesin Volume 3 Nomor 2, Jurusan Teknik Mesin Fakultas Teknologi Industri Universitas Kristen Petra.

Price, E.C and Cheremisinoff,P.N., 1981, Biogas Production and Utilization, Ann Arbor Science Publishere, Inc. United States Of America.

Sciencedirect., 2007 , Proses Pembuatan Biogas, http://www.sciencedirect.com (Download, Juni 2012).

Tirtoatmodjo. Rahardjo., Wilianto., 1999, Peningkatan Performance Motor Bensin 4 Tak 3 Silinder yang Menggunakan Bahan Bakar Gas dengan Penambahan Blower dan Sistem Injeksi, Jurusan Teknik Mesin Fakultas Teknologi Industri, Universitas Kristen Petra.

Fry, L. John, (1973) Methane Digesters for Fuel Gas and Fertilizer. Privately published. 